\title{
Cascatas de Fake News Políticas: um estudo de caso no Twitter
}

\author{
Raquel Recuero ' \\ https://orcid.org/0000-0002-7417-9782 \\ Anatoliy Gruzd " \\ https://orcid.org/0000-0003-2366-5163 \\ I - Universidade Federal de Pelotas \\ Pelotas (RS), Brasil \\ II - Ryerson University \\ Toronto (ON), Canadá
}

Resumo: O presente artigo busca debater, por meio de estudo de caso, as cascatas das chamadas fake news de cunho político no Twitter. Para tanto, examinam-se fake news que circularam durante dois eventos, o julgamento e a prisão do ex-presidente Lula. Para tal análise, utilizam-se métodos de coleta de dados automatizados, análise de redes e uma análise qualitativa. Os principais resultados apontam para uma circulação limitada dessas notícias, principalmente dentro de núcleos ideológicos favoráveis e uma forte ação de determinados tipos de usuários no seu espalhamento.

Palavras chaves: fake news; redes sociais; análise de redes; cascatas.

Abstract: Surges of Political "Fake News": A case study on Twitter. In this paper we propose an analysis of the so-called political "fake news" on Twitter, based on a case study. We examined fake news that circulated during the trial and imprisonment of the Brazilian ex-president Lula da Silva. Through social network and qualitative analyses, we found that this fake news circulated mostly among highly partisan clusters and that their spread is influenced by a certain type of user.

Keywords: fake news, social networks; social network analysis; surges.

\section{Introdução}

O contexto político do Brasil é complexo, pois o país passa por uma crise social, econômica e política que tem se agravado desde o impeachment da então presidenta, Dilma Rousseff, do Partido dos Trabalhadores (PT), em 2016. Neste quadro, a investigação 
e a prisão do ex-presidente Lula, do mesmo partido, no primeiro semestre de 2018, representa um dos momentos mais politicamente tensos desta crise. Isso se refletiu nas discussões que ocorreram na mídia tradicional e na mídia social e, de modo particular, no espalhamento de uma grande quantidade de desinformação e notícias falsas ${ }^{1}$ sobre os fatos. Neste trabalho, examinamos duas cascatas ${ }^{2}$ geradas em cima da difusão do que chamaremos de "fake news políticas" no Twitter em cima deste julgamento. Nosso objetivo é compreender esse processo de desinformação política que tem ocorrido no Brasil, principalmente decorrente do espalhamento de notícias falsas ou fake news na mídia social e, de modo particular, no Twitter. Para tanto, lançamos mão de um estudo de caso focado nessas notícias falsas. Assim, analisaremos: (1) a estrutura dessas "cascatas de fake news" e sua difusão nas conversações políticas; (2) o papel dos diferentes influenciadores nesses processos.

\section{Desinformação e Fake News: Em busca de um conceito}

O conceito de fake news é hoje sinônimo de desinformação, utilizado livremente pelos veículos noticiosos para indicar rumores e notícias falsas que circulam, principalmente, na mídia social. Do mesmo modo, há uma quantidade imensa e variada de informações qualificadas pela literatura dentro deste conceito, compreendendo tanto sátiras, quanto boatos e notícias fabricadas (TANDOC JR., WEI LIM \& LING, 2018). Por isso, para iniciarmos o nosso trabalho, é preciso delimitar o que compreendemos como fake news. Para tanto, trazemos Shu et al. (2017) que apresentam um primeiro caminho, explicitando duas características-chave para este tipo de informação: (1) a falta de autenticidade e (2) seu propósito de enganar. Para os autores, assim, sátiras não seriam fake news, pois revelam sua intenção no próprio discurso e formato. A notícia satírica desvela a sua falsidade pelo humor, não tendo o propósito de enganar. Boatos e rumores também poderiam ser excluídos a partir do conceito, vez que lhes falta o desejo de autenticidade. Parece-nos que a característica do propósito de enganar é fundamental para este trabalho. A fake news, assim, não se trata apenas de uma informação pela metade ou mal apurada, mas de uma informação falsa intencionalmente divulgada, para atingir interesses de indivíduos ou grupos.

Tandoc Jr., Wei Lim \& Ling (2018) explicitam que, por referir-se a "news" ou notícia, o conceito precisaria ser aplicado a informações que emulassem notícias reais, em termos de estilo e linguagem. O mesmo princípio é utilizado por Himma-Kadadas (2017), que acrescenta ainda que as fake news utilizam narrativas jornalísticas e componentes noticiosos, tomando parte nas guerras informativas. O componente noticioso, apontado

1 Por exemplo: <https://brasil.elpais.com/brasil/2018/03/30/politica/1522363863_900510.html><https://www. boatos.org/politica/7-fake-news-lula.html>. Acesso em: 03/05/2018

2 Uma cascata é definida como uma informação que é repassada por atores como se fosse verdadeira, embora estes não tenham como saber se o é (EASLEY \& KLEINBERG, 2010). 
pelos autores, é chave, pois traria para a informação falsa o caráter de credibilidade do jornalismo tradicional, além da aparência de relato de eventos, elemento da notícia jornalística (KOVACH \& ROSENTIEL, 2007). As fake news, assim, tomariam emprestado do jornalismo, pela emulação de seus padrões de linguagem, a credibilidade e a legitimidade para a narrativa falsa que propagam, apoiando-se em sua função social (SHUDSON, 2003; BERTOLINI, 2016). Parece-nos, assim, que esses três elementos seriam essenciais para a definição de uma fake news: (1) o componente de uso da narrativa jornalística e dos componentes noticiosos; (2) o componente da falsidade total ou parcial da narrativa e; (3) a intencionalidade de enganar ou criar falsas percepções através da propagação dessas informações na mídia social. A circulação de notícias falsas, deste modo, atua diretamente na produção de desinformação, de modo particular, na internet, embora não seja o único ambiente usado para isso (SHAO et al., 2018).

Neste trabalho, interessam-nos as fake news eleitorais, ou seja, as notícias criadas com o objetivo de espalhar desinformação e falsas percepções para influenciar processos eleitorais. Buscamos compreender a estrutura de difusão dessas "fake news eleitorais" na mídia social. O conceito de mídia social compreende, necessariamente, a apropriação dos atores dos sites de rede social (BOYD \& ELLISON, 2007) para a difusão de informações. Essas ferramentas constituem-se no substrato que possibilita, pela manutenção de canais de informação permanentemente abertos entre os atores, a difusão das informações de modo mais rápido, mais fiel e mais facilmente escalável.

Não basta apenas a estrutura da rede para que as fake news eleitorais se espalhem. Há dois elementos importantes que "governam" esse espalhamento. O primeiro deles refere-se aos algoritmos de visibilidade dessas ferramentas. Esses algoritmos selecionam o que será visto pelos atores com base em suas próprias ações e nas ações de sua rede social (PARISIER, 2011). O segundo elemento diz respeito às próprias escolhas dos atores, que decidem o que vão compartilhar, publicar ou tornar visível à sua rede social. Assim, mídia social, em âmbito de debate político, também é frequentemente associada à polarização (SOARES, RECUERO \& ZAGO, 2018; GRUZD \& ROY, 2014). Como os atores tendem a compartilhar informações baseadas em suas próprias crenças e percepções, especialmente em contextos polêmicos, a mídia social tende a apresentar redes de conversação extremamente polarizadas. Este fenômeno é representado pela constituição de polos opostos partidarizados, pouco conectados entre si. Nisso, a estrutura das fake news como notícias "verdadeiras" tem valor muito importante, pois cria narrativas que ecoam preconceitos e visões de mundo dos atores sociais (o chamado "bias de confirmação"). Assim, como Horta-Ribeiro et al. (2017) demonstraram em seu trabalho, as pessoas tendem a acreditar em informações que condizem com sua percepção das narrativas sociais e a desacreditar em narrativas que desconstroem essa percepção. Deste modo, a mídia social, por sua estrutura e modos de espalhamento de informação, poderia ampliar a circulação das fake news e, particularmente, daquelas eleitorais. Assim, a circulação 
das fake news poderia afetar também as crenças políticas, constituindo uma esfera pública parcial, partidária e universalizante para aqueles que dela participam.

\section{Cascatas, Fake News e Esfera Pública}

Easley \& Kleinberg (2011) discutem o conceito de cascata de informações para a difusão de informações em redes. Para os autores, uma cascata acontece quando as pessoas decidem de modo sequencial, assistindo as ações das pessoas anteriores e inferindo algo sobre o que as pessoas anteriores sabem. Assim, uma cascata é qualificada pela reprodução de informações baseadas na compreensão do comportamento dos atores anteriores como verdadeiro pelos posteriores, mesmo que estes não tenham como saber. Na mesma linha, Kwak et al (2010) tratam os processos de difusão de informações no Twitter como árvores de retweet (retweet trees). Os autores explicitam que os retweets têm poder importante de influência, relacionado às características de homofilia encontradas nas redes de seguidores.

Homofilia é uma característica das redes sociais conectada ao fato de que as pessoas tendem a ter contato com pessoas similares, em termos de gostos, background etc. (MCPHERSON, SMITH-LOVIN \& COOK, 2001). A homofilia auxilia na compreensão da tendência de uma determinada informação espalhar-se mais dentro de determinado grupo, especialmente em grupos políticos, como o trabalho de Adamic \& Glance (2005) apontou, ao focar blogs políticos e suas relações igualmente polarizadas. Blogs filiados a um mesmo grupo politico tendiam a conectar-se com outros blogs de mesma ideologia, com apenas algumas poucas conexões entre os dois extremos. Esta discussão está diretamente relacionada à criação de bolhas, grupos partidários, por exemplo. Esses grupos são homófilos em termos de partidarismo, crenças e posicionamento político. O efeito câmara de eco, assim, pode facilitar a circulação de fake news eleitorais (SHAH \& KUMAR, 2018). As cascatas de fake news, para os autores, têm características diferentes dos movimentos sociais humanos, pois apenas pequena parcela dos usuários envolvidos é responsável por grande quantidade de manifestações. Outros trabalhos também apontaram para a mídia partidária como especialmente suscetível à propagação de fake news (VARGO, GUO \&AMAZEEN, 2017), de modo particular por conta da homofilia.

O espalhamento de desinformação ou de informação falsa também pode ser influenciado pelos diferentes tipos de atores na rede. Sha \& Kumar (2018) apontam para a influência de robôs (bots) e atores muito engajados que podem criar falsas percepções de consenso, para que determinada informação circule. Esse processo é desenhado por meio da atuação do que Kumar et al. (2017) denominam "lobos solitários", ou seja, usuários humanos que criam certa quantidade de contas falsas para operar sob os mesmos pretextos e premissas, coordenadas de modo a criar falsos consensos e suportes. As redes de bots, assim, operam de modo a (1) aumentar rapidamente a visibilidade 
de uma informação falsa e (2) a inflar o "status" de alguns usuários, fazendo perceber determinada informação falsa como crível. Essas ações potencializam a difusão das notícias falsas, na tentativa de influenciar a esfera pública, com a manipulação artificial de consenso e, do mesmo modo, da opinião pública (FORELLI et al. 2015; SHAO et al., 2018). O trabalho de Bastos \& Mercea (2017) também credita às redes de bots e contas ciborgues no Twitter a articulação para criar e potencializar o espalhamento destas notícias. Os autores identificaram, em seu trabalho, uma organização de contas dedicadas a replicar conteúdo para espalhar desinformação.

\section{Estudo de Caso}

Para que pudéssemos traçar premissas sobre a circulação de fake news eleitorais no contexto das discussões políticas, escolhemos dois eventos que causaram debate político relevante em canais da mídia social. Nosso canal de escolha, devido às restrições impostas pelas novas regras da API para coletas de dados públicos, desde abril de 2018, foi o Twitter.

Os eventos escolhidos foram:

1. O atentado à caravana eleitoral do ex-presidente Lula da Silva, em março de 2018. Lula da Silva, que estava sendo julgado pelo Supremo Tribunal no Brasil, andou em caravana por várias cidades do país em março de 2018. No dia 26 de março, no sul do Paraná, sua caravana foi atacada a tiros por desconhecidos. O evento gerou intenso debate na mídia social.

2. O julgamento do habeas corpus de Lula da Silva. Em 06 e 07 de abril, o STF julgou o último recurso do ex-presidente, determinando-o inválido e autorizando sua prisão, que foi ordenada pelo juiz local, na sequência. Lula da Silva permaneceu por três dias em um sindicato, em São Paulo, negociando sua prisão, apresentando-se à carceragem depois do período. O evento foi acompanhado por todos os veículos noticiosos do Brasil e gerou intenso debate na mídia social.

\section{Procedimentos de coleta de dados}

Para a coleta de dados, utilizamos um crawler com acesso à streaming API do Twitter. Esse crawler coletou tweets a partir da palavra-chave "lula", constituindo um primeiro dataset de 2.430.468 tweets, no período de 01 de fevereiro a 26 de abril de $2018^{3}$. A partir desse dataset, as conversações a respeito dos eventos em questão foram filtradas, utilizando-se palavras-chaves que os descrevessem (Tabela 1). Nestes subconjuntos de dados, buscamos, então, por notícias falsas, apontadas por sites de checagem de notícias

3 É importante salientar que os dados coletados eram dados públicos e abertos e foi ressalvado o anonimato dos sujeitos envolvidos no processo. 
ou veículos jornalísticos, que tivessem sido difundidas nessas conversações. Consideramos fake news políticas de acordo com o que foi explicitado nas sessões anteriores.

\begin{tabular}{|l|l|l|l|l|l|}
\hline & $\begin{array}{l}\text { Atentado } \\
\text { Caravana Lula }\end{array}$ & $\begin{array}{l}\text { Julgamento do } \\
\text { HC de Lula }\end{array}$ & Tweets totais & $\begin{array}{l}\text { Tweets com } \\
\text { as fake news }\end{array}$ & $\begin{array}{l}\text { \% de tweets } \\
\text { com fake news }\end{array}$ \\
\hline $\begin{array}{l}\text { Palavras chaves } \\
\text { assunto }\end{array}$ & $\begin{array}{l}\text { Atentado, } \\
\text { atentados, } \\
\text { caravana }\end{array}$ & $\begin{array}{l}\text { Julgamento, } \\
\text { STF }\end{array}$ & 102525 & 2129 & $2,07 \%$ \\
\hline $\begin{array}{l}\text { Palavras chaves } \\
\text { Fake news }\end{array}$ & $\begin{array}{l}\text { Tiro, tiros, } \\
\text { falso, falsos }\end{array}$ & $\begin{array}{l}\text { Criminosos, } \\
\text { assaltantes, } \\
\text { assassinos }\end{array}$ & 38402 & 4186 & $10,9 \%$ \\
\hline
\end{tabular}

Tab.1. Dados utilizados nesta pesquisa

Assim, foram escolhidos, como fake news:

O julgamento favorável do Supremo Tribunal ao habeas corpus de Lula permitirá que todos os criminosos condenados sejam soltos - A informação é distorcida, vez que a decisão do STF seria apenas aplicável ao caso de Lula. Ela, entretanto, foi publicada em vários sites, com vários formatos diferentes.

Para salvar Lula, STF salva também assassinos e estupradores ${ }^{4}$

Corruptos, estupradores, assaltantes e assassinos serão soltos se Lula ganhar $\mathrm{HC}$ do STF $^{5}$

Este caso é bastante relevante, vez que essas notícias foram reproduzidas no Twitter, associadas à chamada para um protesto no dia 03 de abril (\#vemprarua3deabril), um dia antes do início do julgamento pela Suprema Corte. A informação foi desmentida tanto por veículos associados à esquerda ${ }^{6}$, quanto por veículos jornalísticos ${ }^{7}$ tradicionais no país.

\begin{abstract}
Atentado à caravana de Lula é falso - A informação desmentia o atentado a tiros que ocorreu contra a caravana de Lula, ora dizendo que especialistas teriam duvidado de fatos relacionados ao ataque, ora dizendo claramente que teria sido uma "armação do PT".
\end{abstract}

Jornalista dentro do ônibus entrega: Os tiros foram armação ${ }^{8}$

4 <https://www.oantagonista.com/brasil/para-salvar-lula-stf-salva-tambem-assassinos-e-estupradores/>. Acesso em: 15/05/2018.

$5<$ https://www.noticiasagricolas.com.br/noticias/politica-economia/210906-corruptos-estupradores-assaltantese-assassinos-serao-soltos-se-lula-ganhar-hc-do-stf.html\#.WzOXT1MvxZ0>. Acesso em: 15/05/2018.

$6<$ https://www.diariodocentrodomundo.com.br/a-fake-news-da-invasao-de-criminosos-nas-ruasse-o-stf-conceder-habeas-corpus-a-lula/ e https://catracalivre.com.br/geral/cidadania/indicacao/ mbl-viraliza-informacao-distorcida-sobre-habeas-corpus-de-lula/>. Acesso em: 15/05/2018.

7 <https://epoca.globo.com/politica/noticia/2018/04/o-habeas-corpus-de-lula-no-stf-e-batalha-pela-narrativa-digital. html>. Acesso em: 15/05/2018.

$8<$ https://pensabrasil.com/jornalista-dentro-no-onibus-entrega-pt-foi-tudo-armacao-os-tiros/>. Acesso em: 15/05/2018. 
Policiais experientes não descartam a hipótese de armação para 'vitimizar' no suposto atentado a tiros à caravana do ex-presidente Lula9

Como no primeiro caso, a notícia falsa também foi ampliada, com outras notícias subsequentes e derivadas como, por exemplo, a de que os tiros teriam sido dados pelos próprios militantes do $\mathrm{PT}^{10}$. As notícias falsas também foram desmentidas por veículos jornalísticos ${ }^{11}$, além de veículos vinculados à esquerda ${ }^{12}$.

\section{Procedimentos de Análise de Dados}

A partir dos casos explicitados acima e dos métodos de coleta apontados, mapeamos as redes totais da conversação e as redes das fake news. Para estudar a estrutura dessas redes, utilizamos as métricas da análise de redes sociais (DEGENNE \& FORSÉ, 1999; WASSERMAN \& FAUST, 1994), a partir de softwares de análise como o Gephi ${ }^{13}$. Neste contexto, os nós das redes foram representados por contas no Twitter e as conexões pelos retweets ou menções. Para esta análise, diante dos objetivos apresentados no início da sessão, selecionamos métricas de nó e métricas de rede.

\section{Métricas de Nó}

As métricas utilizadas estão relacionadas a medidas de centralidade, buscando verificar quais nós foram mais centrais para as redes e por quê. As métricas selecionadas foram:

- Indegree (grau de entrada) - O grau de entrada representa o número de conexões diretas que determinado nó recebe dos demais na sua rede. Em termos de conversação no Twitter, o grau de entrada está relacionado à quantidade de vezes que determinado ator é retuitado ou mencionado nos tweets da rede.

- $\quad$ Oudegree (grau de saída) - O grau de saída representa, por sua vez, o número de conexões que determinado nó faz com os demais. Assim, quando determinado ator menciona ou retuíta alguém, há uma conexão produzida por meio daquele tweet.

- Betweenness (centralidade de intermediação) - Esta medida é baseada no número de vezes em que determinado nó faz uma "ponte" entre dois outros nós, ou seja, o número de vezes em que este nó conecta outros pertencentes a clusters (grupos) diferentes. Uma intermediação alta pode mostrar, por exemplo, um nó que tem poder de influência entre dois grupos diferentes, especialmente no que toca aos fluxos de informação no Twitter.

$9<$ https://www.noticiasbrasilonline.com.br/policiais-experientes-nao-descartam-a-hipotese-de-armacao-vitimizar-nosuposto-atentado-a-tiros-a-caravana-do-ex-presidente-lula/>. Acesso em: 15/05/2018.

10 "Falso atentado à caravana do PT pode ganhar a Piada do Ano por antecipação"- <http://www.tribunadainternet. com.br/falso-atentado-a-caravana-do-pt-pode-ganhar-a-piada-do-ano-por-antecipacao/>. Acesso em: 15/05/2018.

$11<$ https://brasil.elpais.com/brasil/2018/03/30/politica/1522363863_900510.html>. Acesso em: 15/05/2018.

$12<$ https://www.pragmatismopolitico.com.br/2018/03/atentado-caravana-de-lula-fake-news.html >. Acesso em: 15/05/2018.

$13<$ https://gephi.org/>. Acesso em: 15/05/2018. 
Finalmente, para melhor compreendermos a qualidade dos nós envolvidos nas cascatas de fake news eleitorais, analisamos os 20 nós com maior grau em cada uma das métricas de nó. Para essa avaliação, analisamos: (1) identificação do perfil (por exemplo, se o perfil é anônimo ou não); (2) atividade do nó (por exemplo, número de curtidas e comentários); (3) tamanho da rede do nó (número de contas seguidoras e seguidas): e (4) os últimos 30 tweets publicados por cada conta. Nosso objetivo, aqui, foi perceber qual papel os nós apresentaram nessa estrutura.

\section{Métricas de Rede}

Além das métricas que utilizaremos para discutir a posição dos nós na rede, também trabalharemos com outras para discutir a estrutura da rede. Para tal discussão, escolhemos as medidas que se seguem:

- Coeficiente de clusterização médio - Esta métrica é utilizada para apontar o quanto um nó determinado tende a conectar-se com um grupo e, em termos de média, portanto, o quão clusterizada uma rede é. Em nosso caso, o coeficiente de clusterização médio pode indicar o quão próximos estão os nós na conversação, bem como indicar também a presença de clusters (grupos de nós que se citam mutuamente).

- Caminho médio entre os nós - O caminho médio entre os nós representa a distância média entre eles. Quanto menor, mais conectada esta rede. Em termos de conversação, o caminho médio indica o quão distantes estão os nós entre si na conversação, podendo oferecer inferências a respeito do quão longe as informações transitam na rede.

- Diâmetro da rede - Esta é outra métrica que permite verificar quão interconectada está a rede analisada. Quanto maior o diâmetro, mais "espalhada" é a rede. O diâmetro complementa o caminho médio, indicando o maior caminho na rede. Em termos de conversação, ele também pode indicar o quão longe determinada informação foi na rede.

Essas três métricas são complementares, na medida em que o grau de clusterização médio nos mostra a média de conexão dos nós na rede, ou seja, o quão agrupados estão entre si, desvelando, por exemplo, a presença de clusters na conversação. Já o caminho médio complementa essa métrica, mostrando o quão próximos estão os nós envolvidos na conversação, enquanto o diâmetro mostra a distância máxima entre esses nós.

\section{Estudo de Caso: Estrutura das Cascatas de Fake News}

Para compreender a estrutura das cascatas de fake news políticas, discutimos primeiro as redes "contexto" das conversações em que foram capturadas. A seguir, discutimos as redes de desinformação a partir da comparação com as redes de conversação. 


\section{Redes de Fake News}

Primeiramente, observamos que as redes de conversação capturadas são altamente polarizadas (Figuras 1 e 2) ${ }^{14}$. Os clusters foram identificados de modo automático, baseados em algoritmo de detecção de comunicades apresentado por Blondel et al. (2008). A identificação de determinado nó dentro do cluster específico está relacionada a uma maior probabilidade de aquele nó interagir com os demais nós do cluster, versus interagir com os nós de outros grupos a partir dos dados observados. Os dados das redes estão resumidos na tabela 2 .

\begin{tabular}{|l|l|l|l|l|}
\hline & $\begin{array}{l}\text { Rede inteira 1: } \\
\text { Caravana Lula }\end{array}$ & $\begin{array}{l}\text { Rede de Fake News } \\
\text { 1: Caravana Lula }\end{array}$ & $\begin{array}{l}\text { Rede Inteira 2: } \\
\text { Julgamento de Lula }\end{array}$ & $\begin{array}{l}\text { Rede de Fake News } \\
\text { 2: Julgamento de } \\
\text { Lula }\end{array}$ \\
\hline Número de Nós & 38402 & 4148 & 102525 & 2129 \\
\hline Número de Arestas & 98987 & 4974 & 243431 & 2130 \\
\hline $\begin{array}{l}\text { Nós filiados } \\
\text { ao cluster da } \\
\text { esquerda }\end{array}$ & $29,39 \%$ & $5,9 \%$ & $26,71 \%$ & $0,12 \%$ \\
\hline $\begin{array}{l}\text { Nós filiados ao } \\
\text { cluster da direita }\end{array}$ & $24,33 \%$ & $81,53 \%$ & $21,27 \%$ & $78,58 \%$ \\
\hline
\end{tabular}

Tab. 2. Dados das Redes Analisadas

Os dois clusters que aparecem e ambas as conversas capturam a maior parte dos nós (próximo a 50\% dos nós, nos dois casos), indicando concentração da discussão em torno de alguns atores. Podemos observar também que cada um dos clusters em questão envolve grande número de nós partidários de esquerda ou de direita, porém não de ambos. Ou seja, cada cluster tende a concentrar grande número de atores com uma única visão polarizada, com poucas pontes para o outro grupo. A Tabela 3 mostra as métricas dessas redes inteiras.

\begin{tabular}{|l|l|l|}
\hline & $\begin{array}{l}\text { Rede 1: } \\
\text { Ataque à Caravana de Lula }\end{array}$ & $\begin{array}{l}\text { Rede 2: } \\
\text { Julgamento da prisão de Lula }\end{array}$ \\
\hline$\%$ de nós nos clusters maiores & $53,72 \%$ & $47,98 \%$ \\
\hline Caminho médio & 9,80 & 4,42 \\
\hline $\begin{array}{l}\text { Coeficiente de clusterização } \\
\text { médio }\end{array}$ & 0,02 & 0,07 \\
\hline Diâmetro & 20 & 12 \\
\hline
\end{tabular}

Tab. 3. Redes observadas

14 Para a visualização das redes, utilizamos um algoritmo de força, como o Yfan-Hu (2006), de modo a aproximar os nós mais conectados e repulsionar os nós menos conectados. 
Conforme vimos nas tabelas 2 e 3, a Rede 2 é a maior em termos de nós envolvidos. Entretanto, aqui vemos que é a rede com menor diâmetro (portanto, mais interconectada) e com menor caminho médio. Isso indica que há uma participação expressiva dos nós mais centrais nessas redes, atuando como conectores e aproximando a rede dentro dos clusters. O coeficiente de clusterização médio também é maior, implicando em uma rede mais conectada. Ou seja, podemos dizer que esta rede, apesar de mais conectada, é menos polarizada (uma vez que envolve menos nós nos clusters principais e tem diâmetro menor). Já a Rede 1, embora menor e menos conectada, tem percentual superior de nós vinculados aos clusters. Essa rede, portanto, é mais polarizada, pois tem tamanho maior (diâmetro) e mais espalhada (com um caminho médio também maior). Assim, a conversação na primeira rede é mais dispersa e menos clusterizada em torno dos mesmos nós.

Os formatos dessas redes, conforme vemos nas Figuras 1a e 1b, mostram essa polarização de modo mais explícito. A implicação desta polarização é a de que esses clusters constituem-se em câmaras de eco (SUNSTEIN, 2001), construídas principalmente através da ação de filtragem dos nós, que impedem que os tweets dos nós que não estão alinhados ideologicamente com seu grupo não circulem ali (PARISIER, 2011). Com uma exposição limitada à informação contraditória, os atores envolvidos seriam menos capazes de discernir entre as informações verdadeiras e falsas e, igualmente, entre as informações parciais ou falsas que circulam em seus grupos. A polarização encontrada nessas conversações em muito se assemelha a outras encontradas em estudos da esfera pública política na internet (ADAMIC \& GLANCE, 2005). Essa esfera pública está centrada em clusters partidários, o que também indica o papel importante da homofilia (MCPHERSON, SMITH-LOVIN \& COOK,2001), uma vez que podemos presumir que nós com visões políticas semelhantes tendem a estar mais conectados.

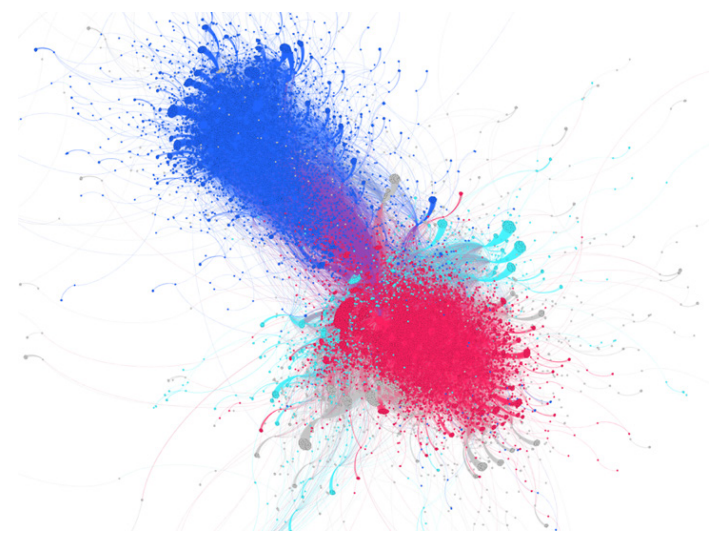

Fig. 1a: Rede do ataque à caravana de Lula. O cluster vermelho contém os nós mais identificados com partidos de esquerda, que apoiavam o ex-presidente e, no cluster azul, aqueles contrários, mais identificados com partidos de direita. Os nós em azul claro representam grupos não filiados. 


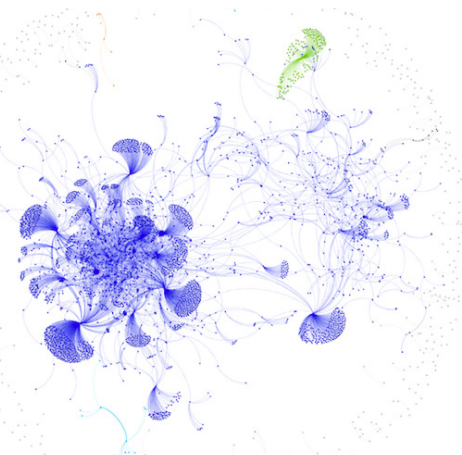

Fig. 1b. Cascata à fake news ataque à caravana de Lula. O cluster azul apresenta nós que no grafo anterior estavam presentes no cluster partidos de direita.

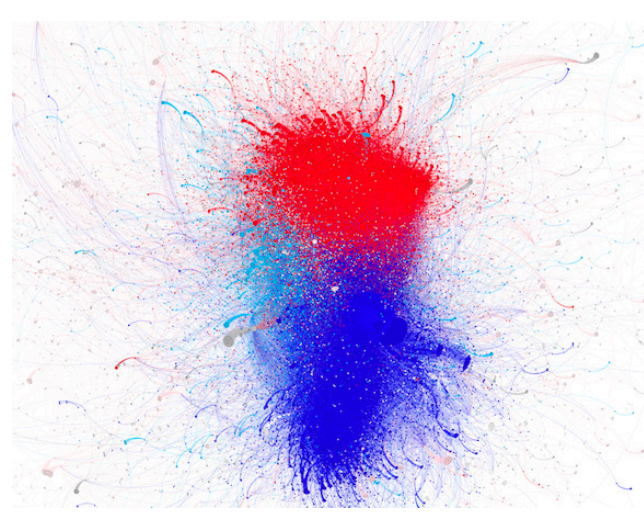

Fig. 2. Rede de conversação em torno do julgamento de Lula. O cluster vermelho contém os nós mais identificados com partidos de esquerda, que apoiavam o ex-presidente e, no cluster azul, aqueles contrários, mais identificados com partidos de direita. Os nós em azul claro representam grupos não filiados.

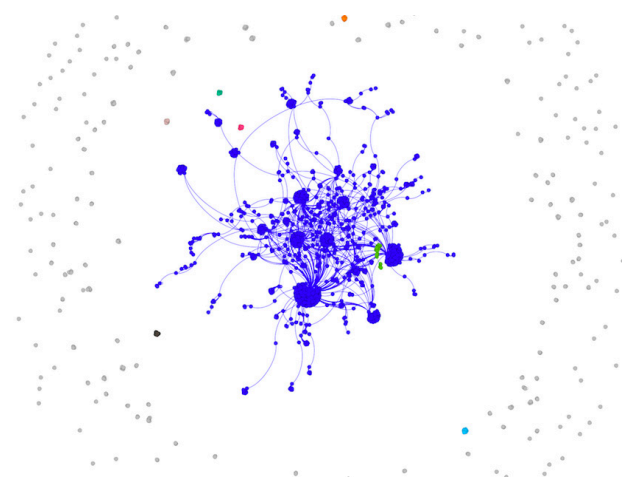

Fig.2b. Cascata referente às fake news sobre o julgamento de Lula.

O cluster azul apresenta nós que no grafo anterior estavam presentes no cluster de direita. 
Já as cascatas de fake news aparecem nas figuras 2a e 2b. Elas têm estrutura bastante diferente (Tabela 4). São redes primeiramente bem menores do que as anteriores, com diâmetro pequeno. Além disso, a maioria dos nós envolvidos nessas redes (praticamente a totalidade deles) está dentro do mesmo cluster da rede anterior, o cluster da direita. Essas redes também têm um caminho médio pequeno (em torno de uma conexão apenas) e um coeficiente de clusterização médio muito baixo. Esses dados sugerem que as fake news analisadas tiveram sua circulação bastante limitada na rede, não conseguindo espalhar-se além de uma pequena distância dos nós imediatamente conectados. Os dados sugerem também que essas informações se espalharam principalmente entre nós alinhados ideologicamente com o viés do conteúdo (direita), circulando principalmente em seu próprio cluster ideológico.

A tabela 4 também mostra que a segunda rede (relativa à informação de que o julgamento favorável ao recurso de Lula soltaria imediatamente centenas de criminosos) espalhou-se mais, com diâmetro da rede maior, com caminho médio também maior. O coeficiente de clusterização médio também maior entre os nós participantes aponta para maior envolvimento de nós interconectados na rede no processo de difusão. A rede, conforme vimos nas tabelas 1 e 2, é, apesar disso, menor. Já a Rede 1 tem um conjunto maior de nós envolvidos, porém espalha-se menos, com diâmetro menor, e caminho médio menor. A média do coeficiente de clusterização também é menor, indicando nós menos conectados entre si no processo.

\begin{tabular}{|l|l|l|}
\hline & $\begin{array}{l}\text { Rede 1: Ataque } \\
\text { à Caravana de Lula }\end{array}$ & Rede 2: Julgamento de Lula \\
\hline$\%$ cluster da Direita & $81,53 \%$ & $78,58 \%$ \\
\hline$\%$ Cluster da Esquerda & $5,90 \%$ & $0,12 \%$ \\
\hline Caminho médio & 1,06 & 1,20 \\
\hline $\begin{array}{l}\text { Coeficiente de clusterização } \\
\text { médio }\end{array}$ & 0,008 & 0,02 \\
\hline Diâmetro da rede. & 3 & 4 \\
\hline
\end{tabular}

Tab. 4. Dados das Redes de Fake News

Os dados que vimos aqui apontam para o fato de que os clusters parecem circular fake news que concordam com seu próprio ponto de vista ideológico (AZZIMONT \& FERNANDES, 2017), reforçando suas visões das narrativas políticas. Esse elemento já foi apresentado na literatura por Kumar \& Shah (2018), sugerindo que os clusters ideológicos, em redes polarizadas, seriam ambientes ideais para a circulação de notícias falsas. Esses resultados também estão conectados às observações de Vargo, Guo e Amazeen (2017), que apontam que as fake news encontram na mídia partidária um espaço bastante propício para sua circulação. Neste sentido, observamos que não. As fake news observadas ficam restritas a seus clusters de origem, sem conseguir ultrapassar os limites dos clusters contrários. Essa circulação pode atuar de modo a reforçar as narrativas que já circulam nesses ambientes. 


\section{Nós na estrutura das Redes}

Nesta sessão, discutiremos os diferentes papéis que os nós mais centrais tiveram no espalhamento das cascatas de fake news na rede. Para tanto, analisamos os 20 nós com maior grau em cada métrica e em cada rede. Cada um destes perfis foi analisado a partir da identificação da conta (elementos como uso de nome próprio ou pseudônimo, fotografia, fundo do perfil e descrição, bem como número de seguidores, número de seguidos, número de favoritos e de tweets publicados) e os últimos vinte tweets publicados. A partir destes elementos, as contas foram classificadas em cinco categorias:

- Líderes de opinião: Contas com um grande número de seguidores (sempre superior ao número de contas seguidas), com usuários não-anônimos. Geralmente compreendiam jornalistas, políticos ou pastores. O conteúdo dos tweets analisados foi mais variado.

- Ativistas políticos: Contas com um número menor de seguidores. Em comum, possuem um conteúdo fortemente partidário e sob um mesmo viés ideológico. Geralmente identificadas como "patriotas", com fortes referências a elementos relacionados ao Brasil (hino, Bandeira, cores etc.). Essas contas podem ser anônimas ou conter indícios de anonimato e são geralmente muito ativas.

- Veículos midiáticos: Contas que se autoidentificavam como "mídia". Algumas identificavam-se como veículos alternativos, outras são contas reconhecidas de jornais.

- Instituições: Contas oficiais relacionadas a órgãos do governo, à Suprema Corte ou tribunais.

Essas categorias compreendem aquelas contas identificadas a partir das métricas que discutiremos a seguir. A prevalência de cada tipo de conta, por métrica, em cada uma das redes está disposta a seguir (Tabela 5):

\begin{tabular}{|l|l|l|l|l|l|l|}
\hline \multicolumn{2}{|l|}{ Rede 1 Ataque à caravana de Lula } & \multicolumn{2}{l|}{ Rede 2 Julgamento de Lula } \\
\hline Métrica & $\begin{array}{l}\text { Grau de } \\
\text { Entrada }\end{array}$ & $\begin{array}{l}\text { Grau de } \\
\text { Saída }\end{array}$ & Intermediação & $\begin{array}{l}\text { Grau de } \\
\text { Entrada }\end{array}$ & $\begin{array}{l}\text { Grau de } \\
\text { Saída }\end{array}$ & Intermediação \\
\hline Ativista & 10 & 22 & 19 & 9 & 29 & 24 \\
\hline $\begin{array}{l}\text { Veículo } \\
\text { midiático }\end{array}$ & 2 & 0 & 0 & 4 & 1 & 0 \\
\hline $\begin{array}{l}\text { Líder de } \\
\text { opinião }\end{array}$ & 8 & 0 & 2 & 6 & 0 & 1 \\
\hline Instituições & 0 & 0 & 1 & 1 & 0 & 0 \\
\hline
\end{tabular}

Tab. 5. Nós principais a partir da classificação criada 
Na tabela 5, vemos que a maioria dos nós observados nas duas redes enquadrase na categoria "ativista político". Também podemos observar que, nas duas redes, há mais nós diferentes no grau de intermediação (líderes de opinião, instituições e veículos midiáticos), indicando que mais nós diferentes são citados. A citação de nós diferentes, como líderes de opinião, veículos e instituições, pode ser uma estratégia também para legitimação das narrativas das fake news utilizada por ativistas. A forte presença de contas ativistas também é algo relevante para observarmos. Analisando essas contas (Tabela 6), pudemos perceber, primeiramente, que há forte atividade em termos de curtidas e tweets, muitas vezes, de modo desproporcional à rede de seguidores, por exemplo. Outro dado relevante aponta para o fato de que cinco das contas individualmente avaliadas nas duas redes foram suspensas em momento posterior, pelo Twitter. Esses dados sugerem, por exemplo, uma automatização das contas em questão, conforme Bastos \& Mercea (2017) já haviam sugerido em seu trabalho.

\begin{tabular}{|l|l|l|}
\hline Contas ativistas com maior outdegree & $\begin{array}{l}\text { Cascata 1: Ataque à } \\
\text { Caravana de Lula }\end{array}$ & $\begin{array}{l}\text { Cascata 2: Julgamento de } \\
\text { Lula }\end{array}$ \\
\hline Média do número de tweets & $157.081,2$ & $1.278 .132,79$ \\
\hline Média do número de likes & $906.403,98$ & $412.854,72$ \\
\hline Média de contas seguidas & 1438,2 & $10.754,68$ \\
\hline Média de seguidores & 2519,1 & $19.021,85$ \\
\hline
\end{tabular}

Tab. 6. Atividade das contas ativistas

\section{Cascatas de Fake News Eleitorais}

A partir do que pudemos observar nos casos estudados, podemos delimitar algumas características das cascatas de fake news que observamos. Vemos que as contas "ativistas" parecem ser as principais responsáveis pelo espalhamento dessas informações. Elas não apenas são responsáveis pela articulação e espalhamento dessas notícias (a maioria das contas com maior grau de saída e grau de intermediação), como também utilizam contas institucionais e de lideranças como menções, amplificando o espalhamento das informações e dando-lhes credibilidade (vemos que a maioria dessas contas, por exemplo, está entre aquelas que possuem maior grau de entrada (maior número de citações), o que amplia a visibilidade da cascata.

Assim, percebemos que aqueles nós responsáveis pelo espalhamento das informações, com maior grau de saída, utilizam-se de citações e menções a outros nós, como líderes de opinião e instituições, para conquistar credibilidade à notícia. Em alguns casos, 
há líderes de opinião que acabam retuitando a notícia e, com isso, contribuem para a sua visibilidade. Finalmente, os veículos midiáticos encontrados, em geral, são contas que se autodenominam "jornais", possivelmente de baixa credibilidade e associadas ao próprio início da cascata de "fake news". Ambas as redes possuem estruturas bastante semelhantes neste sentido, com grande número de nós ativistas que têm papel importante na ativação e no início das cascatas, principalmente através de retweets, conforme outros autores, como Kwak et al (2010), já tinham observado. Essas estratégias são condizentes e complementares com aquelas apontadas por Kumar et al. (2017). Primeiramente, observamos que há um conjunto de nós altamente engajados, com grande atividade (em muitos momentos, inclusive, desproporcional à rede à qual estão vinculados), que são os principais responsáveis pelo espalhamento dessas informações falsas. Mais do que isso, vemos que muitos desses nós atuam como "lobos solitários", retuitando a mesma informação diversas vezes, mencionando líderes de opinião e constas institucionais, em uma tentativa de angariar visibilidade e credibilidade para essas contas. Parecem operar a partir das premissas indicadas pelo autores de (1) aumento da visibilidade de uma informação falsa e (2) inflar o "status" de quem a publica, seja através de retweets, seja através da citação de veículos oficiais. Esses dados podem sugerir, também, a presença de contas automatizadas, responsáveis pela tentativa de dar visibilidade de modo artificial às fake news.

\section{Conclusões}

Nosso objetivo, neste, artigo foi examinar duas cascatas de "fake news políticas" relacionadas ao caso do julgamento e prisão do ex-presidente Lula. Dissemos que nossos objetivos eram 1) a estrutura dessas "cascatas de fake news" e sua difusão nas conversações políticas; (2) o papel dos diferentes influenciadores. Quanto à estrutura, observamos que as fake news, em nosso caso, não conseguem propagar-se além dos clusters ideológicos aos quais estão filiadas, influenciando, deste modo, apenas aqueles atores já presentes nessas câmaras de eco. Além disso, observamos que os casos específicos não se constituem em notícias largamente espalhadas, mas em cascatas relativamente pequenas. Vimos também que essas cascatas são constituídas fortemente por conjuntos de atores bastante engajados, ou ativistas políticos, que utilizam a citações de líderes de opinião e veículos midiáticos para auxiliar possivelmente na conquista de credibilidade dessas notícias e seus possíveis espalhamentos. Esses nós acabam por citar determinados influenciadores ou nós mais populares. Na média, há poucas pontes, o que explica a dificuldade dessas notícias saírem de seu próprio núcleo ativista. As características de homofilia presentes nos clusters ideológicos das conversações analisadas podem reforçar a polarização e relacionar esses clusters a ações de filtragem ideológica, de modo a reforçar posições partidárias. Essas características podem auxiliar na compreensão de porquê as cascatas observadas parecem não atingir os atores que estão fora deste cluster, nem mesmo para 
que sejam desmentidas. Ao contrário, essas cascatas parecem acontecer apenas entre nós já identificados com a posição política que as fake news valorizam. Nossos resultados sugerem que as fake news eleitorais ficam restritas a seus próprios clusters ideológicos. No entanto, é importante observar que, mesmo a circulação dessas fake news dentro de grupos em que há homofilia, pode aumentar a clusterização da rede pela ação das câmaras de eco, aumentando também o extremismo e as crenças políticas, o que contribui para constituir uma esfera pública parcial, com falsa percepção de consenso. Esse detalhe é particularmente complicador para as democracias em momentos eleitorais, como o que vive o Brasil atualmente. Além disso, a própria ação artificial, no sentido de gerar consenso, conforme encontramos evidências, pode também ter efeitos nessa construção.

Raquel Recuero é professora da Universidade Federal de Pelotas. Coordenadora do MIDIARS (Laboratório de pesquisa em Mídia, Discurso e Análise de Redes Sociais), professora e pesquisadora da UFPEL e da UFRGS e pesquisadora do CNPQ.

raquelrecuero@gmail.com

Anatoliy Gruzd é coordenador do Social Media Lab e professor na Ryerson University.

gruzd@ryerson.ca

\section{Referências}

ADAMIC, L. \& GLANCE, N. The Political Blogosphere and the 2004 U.S. Election: Divided They Blog. March 2005. Disponível em: <http://www.ramb.ethz.ch/CDstore/www2005-ws/workshop/ wf10/AdamicGlanceBlogWWW.pdf>. Acesso em 20 jul 2018.

BASTOS, M. T. \& MERCEA D. The Brexit Botnet and User-Generated Hyperpartisan News. Social Science Computer Review, 2017. DOI: 10.1177/0894439317734157. Acesso em 20 jul 2018.

BOYD, D.M.; ELLISON, N.B. Social network sites: definition, history, and scholarship. Journal of Computer-Mediated Communication, v. 13, n. 1, p. 210-230, 2007. Disponível em: <http://jcmc. indiana.edu/vol13/issue1/boyd.ellison.html>. Acesso em: 3 dez 2011.

BERTOLINI, J. O contrato social da imprensa: por um Leviatã do jornalismo. Rizoma, Santa Cruz do Sul, v. 4, n. 1, p. 208, agosto, 2016. Doi: http://dx.doi.org/10.17058/rzm.v3i1.6673. Acesso em 20 jul 2018.

BLONDEL, V., GUILLAUME, J-L.; LAMBIOTTE, R.; LEFEBVRE, E. Fast unfolding of communities in large networks. In: Journal of Statistical Mechanics: Theory and Experiment 2008 (10), P1000.

DEGENNE, A. \& FORSÉ, M. Introducing Social Networks. Sage: London, 1999

Easley, D. \& Klleinberg, J. Networks, Crowds, and Markets: Reasoning about a Highly Connected World. Cambridge University Press, 2010. Disponível em: <http://www.cs.cornell.edu/home/kleinber/ networks-book/>. Acesso em 20 jul 2018.

FORELLI, M.; HOWARD, P.; MONRÓY-HERNAÁNDEZ, A.; SAVAGE, S. Political Bots and the Manipulation of Public Opinion in Venezuela. 2005. Disponível em: <eprint arXiv:1507.07109>. 
Acesso 20 de jul2018.

GRUZD, A. \& ROY, J. Investigating Political Polarization on Twitter: A Canadian Perspective. Policy \& Internet. Vol 6, Issue 1, 2014. DOI: <https://doi-org.ezproxy.lib.ryerson.ca/10.1002/1944-2866. POI354>. Acesso em 20 jul 2018.

HIMMA-KADAKAS, M. Alternative facts and fake news entering journalistic content production cycle. Cosmopolitan Civil Societies: An Interdisciplinary Journal Vol 9 No 2 (2017). DOl: <https:// doi.org/10.5130/ccs.v9i2.5469>. Acesso em 20 de jul2018.

HORTA-RIBEIRO, M.; CALAIS, P. H.; ALMEIDA, V. Everything I disagree with is fake news. Correlating Political Polarization and Spread of Misinformation. Disponível em: <https://arxiv.org/ abs/1706.05924>. Acesso em 20 de jul 2018.

KWAK H., LEE, C., PARK, H., MOON, S. What is Twitter, a Social Network or a News Media? International World Wide Web Conference Committee (IW3C2). WWW 2010, April 26-30, 2010, Raleigh, North Carolina, USA. Disponível em: <https://an.kaist.ac.kr/ haewoon/papers/2010-wwwtwitter.pdf>. Acesso em 20 de jul 2018.

KOVACH, B.; ROSENSTIEL, T. The Elements of Journalism: What Newspeople Should Know and The Public Should Expect. 1st rev ed. New York: Three Rivers Press, 2007.

KUMAR, S., CHENG, J.; LESKOVEC, J.; SUBRAHMANIAN, V.S. An army of me: Sockpuppets in online discussion communities. In: Proceedings of the 26th International Conference on World Wide Web, 2017. Disponível em: <https://arxiv.org/abs/1703.07355>. Acesso em 20 jul2018.

MCPHERSON, M.; SMITH-LOVIN, L.; COOK, J. M. Birds of a feather: Homophily in social networks. Annual Review of Sociology, 27(1):415-444, 2001.

PARISIER, E. The Filter Bubble. New York: The Penguin Press, 2011.

SOARES, F. B. ; RECUERO, R. ; ZAGO, G. Influencers in Polarized Political Networks on Twitter. In: Proceedings for the International Conference for Social Media and Society. Copenhagen, Denmark, 2018. p. 1-10.

SHAH, N.; KUMAR, L. False Information on Web and Social Media: A Survey. Arxiv. Disponível em: $<$ https://arxiv.org/pdf/1804.08559.pdf>. Acesso em 20 de jul 2018.

SHAO, C.; CIAMPAGLIA, G.L.;VAROL, O.; FLAMMINI, A \& MENCZER, F. The spread of low-credibility content by social bots. Disponível em: <https://arxiv.org/abs/1707.07592v4>. Acesso em 20 jul 2018.

SHU, K.; SILVA, A.; WANG, S.; JANG, J.; LIU, H. Fake news detection on social media: a data mining perspective. Arxiv, 2017. Disponível em <<https://arxiv.org/abs/1708.01967>>. Acesso em 20 jul 2018.

SCHUDSON, M. The Sociology of News. New York: W.W. Norton \& Company, Inc, 2003.

SUNSTEIN, C. Echo Chambers. Princeton: Princeton University Press, 2001.

TANDOC JR., E. WEI LIM, Z \& LING, R. Defining “Fake News". Digital Journalism, 6:2, 2018, p. 137-153, DOI: 10.1080/21670811.2017.1360143

VARGO, C.; GUO, L.; AMAZEEN, M. The agenda-setting power of fake news: A big data analysis of the online media landscape from 2014 to 2016. New Media \& Society. Vol 20, Issue 5, pp. 2028-2049, 2017. DOI: <https://doi-org.ezproxy.lib.ryerson.ca/10.1177/1461444817712086>. Acesso em 30 de ago 2018.

WASSERMAN, S. e FAUST, K. Social Network Analysis. Methods and Applications. Cambridge, UK: Cambridge University Press, 1994. 